\title{
Farklı bitki büyümeyi düzenleyici maddelerin ‘Hayward’ kivi çeşidinin biyokimyasal içerikleri üzerine etkisi
}

The effect of different plant growth regulators on the biochemical contents of the 'Hayward' kiwi cultivar

\section{Umut BALIKÇI ${ }^{1}$ (D) Adnan Nurhan YILDIRIM ${ }^{1 / \infty}$ (D) , Civan ÇELiK $^{2}$ (i)}

${ }^{1}$ Isparta University of Applied Sciences, Faculty of Agriculture, Department of Horticulture, Isparta, Turkey.

${ }^{2}$ Isparta University of Applied Sciences, Faculty of Agriculture, Department of Agricultural Biotechnology, Isparta, Turkey.

\section{MAKALE BILGISI / ARTICLE INFO}

\section{Makale tarihçesi / Article history:}

DOI: $10.37908 /$ mkutbd.905959

Geliş tarihi /Received:30.03.2021

Kabul tarihi/Accepted:04.05.2021

\section{Keywords:}

Actinidia deliciosa, kiwifruit, hayward, total phenolic, total flavonoid.

\footnotetext{
Corresponding author: A.N. YILDIRIM

$\bigotimes$ : adnanyildirim@isparta.edu.tr
}

\section{Ö Z E T / A B S T R A C T}

Atıf / Citation: Balıkçı U, Yıldırım AN, Çelik C (2021) Farklı bitki büyümeyi düzenleyici maddelerin 'Hayward' kivi çeşidinin biyokimyasal içerikleri üzerine etkisi. MKU. Tar. Bil. Derg. 26(2) : 337-344. DOI: 10.37908/mkutbd.905959

\section{Giriş}

Kivi (Actinidia deliciosa), Actinidiaceae familyası içerisinde, Actinidia cinsine ait bir bitkidir. Bu cinsin tamamı Asya kökenli olup, 50'den fazla tür içermekte ancak bunun sadece 5 türü meyve olarak tüketilmektedir. Bu türler Actinidia deliciosa, $A$. chinensis, A. arguta, A. kolomikta ve A. briantha'dır. Ekonomik öneme sahip olan türler ise A.deliciosa ve
A.chinensis'dir (Ferguson, 1991). Kivi diğer meyve türleri ile kıyaslandığında daha geç dönemde kültüre alınmış ve son 15-20 yıldır Akdeniz ülkelerinde yetiştirilmeye başlanmıştır. Turunçgiller ve elma türleri ile kıyaslandığında C vitamini, A vitamini, E vitamini, kalsiyum, demir, magnezyum ve potasyum bakımından oldukça zengin bir meyvedir (Anonim, 2011). Kivi meyvesinin, insanların sağıı bilincinin artması, sağlık açısından öneminin anlaşılması ve daha geniş kitleler ile 
buluşmasından dolayı dünya çapında üretimi gün geçtikçe artmaktadır. FAO, 2019 verilerine göre dünya kivi üretimi 6544738 tona ulaşmıştır. Bu üretimin \%33.56'sını Çin (2 196727 ton) karşılamakta ve üretimde ilk sırada yer almaktadır. Yeni Zellanda \%8.52 (558 191 ton) üretim ile ikinci sırayı almaktadır. Ülkemiz çok geç üretime başlamış olsa da \%0.97 (63 798 ton) ile dünya üretiminde yedinci sırada yerini almıştır (FAO, 2019).

TÜik verilerine göre ülkemizde 2020 yılında 73745 ton kivi üretimi gerçekleşmiştir. Üretimde \%38.53 (28 416 ton) ile Yalova ili birinci sırayı alırken bunu \%14.48 (10 680 ton) ile Bursa, \%11.15 ile Ordu illeri takip etmiştir (TÜiK, 2020).

Kivinin Dünya'da ticari öneme sahip kültür çeşitleri "Hayward", "Bruno", "Allison" ve "Monty" dir. Ülkemizde de en çok yetiştirilen çeşit "Hayward" 'dır. Hayward çeşidi lezzeti, besin değeri, meyve iriliği ve verimi, muhafaza süresinin uzunluğu gibi nedenlerle en çok yetiştirilen çeşittir (Samancı, 1990). Ancak üretilen meyvenin kalitesinde sorunlar meydana gelmektedir. En önemli kalite sorunları erken hasat ve bitki büyümeyi düzenleyicilerin bilinçsizce kullanılmasıdır. Kahraman ve ark. (2018) kivi meyvesinin kalite ve verimini, bahçe tesisi, çiçeklenme öncesi ve çiçeklenme döneminde meyve kalitesini etkileyen uygulamalar, meyve tutumu sonrasında meyve kalitesini etkiyen uygulamalar ve hasat zamanında meyve kalitesini etkileyen uygulamalar şeklinde sınıflandırmıştır.

Çalışmada, farklı bitki büyümeyi düzenleyici maddelerin kivi meyvesinin biyokimyasal içerikleri üzerine etkiler araştırılmıştır. Bu amaçla omcalara, Forchlorfenuron (CPPU), Giberellik Asit $\left(\mathrm{GA}_{3}\right)$, Okzalik Asit (OA), Indol Bütirik Asit (IBA) ve Perlan uygulanmış ve hasat zamanında meyveler toplanıp biyokimyasal analizler yapılmıştır.

\section{MATERYAL ve YÖNTEM}

Çalışma Bartın ilinde 2009 yılında 2.5 x 5 m dikim sıklığına sahip 'Hayward' kivi çeşidi ile tesis edilmiş bahçede yürütülmüştür. Çalışma 2019 yılında tesadüf parselleri deneme desenine göre 3 tekerrürlü ve her tekerrürde 1 omca olacak şekilde planlanmıştır. Araştırmada tozlayıcı olarak Matua çeşidi 1:8 oranında kullanılmıştır. Araştırmada pomolojik ve biyokimyasal özelliklerin belirlenmesi için tekerrürde 10 meyve olacak şekilde toplam 30 meyve kullanılmıştır. Araştırma bahçesinde yapılan toprak analiz sonuçları Çizelge $1^{\prime}$ de verilmiştir. Buna göre toprak pH değeri bakımında hafif alkali, kireçli ve mineral madde içerikleri bakımından yeterlidir. Ayrıca organik madde içeriği bakımından orta olduğu saptanmıştır.

Çizelge 1. Araştırma alanının toprak analiz sonuçları

Table 1. Results of soil analyses that research area

\begin{tabular}{lllll}
\hline Analiz Parametreleri & Birim & Metodlar & Analiz sonucu & Değerlendirme \\
\hline $\mathrm{pH}$ &. & Saturasyon & 7.7 & Hafif Alkalin \\
Kireç & $(\%)$ & Kalsimetrik & 11.5 & Kireçli \\
Tuz & $(\%)$ & Saturasyon & 0.045 & Tuzsuz \\
Doygunluk & $(\%)$ & Saturasyon & 98 & Kil \\
Organik madde & $(\%)$ & TS 8336 & 2.82 & Orta \\
Toplam N & $(\%)$ & Kjeldahl & 0.103 & Yeterli \\
Bitkiye Yarayışı। P & $\mathrm{kg} \mathrm{P}_{2} \mathrm{O}_{5} / \mathrm{da}$ & İşletme İ̧̧i metot & 11.42 & Az \\
Bitkiye Yarayışı K & $\mathrm{kg} \mathrm{P}_{2} \mathrm{O}_{5} / \mathrm{da}$ & A.Asetat-ICP & 73 & Yeterli \\
Ekstrakte Edilebilir $\mathrm{Ca}$ & $\mathrm{kg} \mathrm{P}_{2} \mathrm{O}_{5} / \mathrm{da}$ & A.Asetat-ICP & 2136.8 & Fazla \\
Ekstrakte Edilebilir $\mathrm{Mg}$ & $\mathrm{kg} \mathrm{P}_{2} \mathrm{O}_{5} / \mathrm{da}$ & A.Asetat-ICP & 116.9 & Yeterli \\
Bitkiye Yarayışı $\mathrm{Fe}$ & $(\mathrm{ppm})$ & DTPA-ICP & 7.68 & Yeterli \\
Bitkiye Yarayışı $\mathrm{Mn}$ & $(\mathrm{ppm})$ & DTPA-ICP & 1.53 & Orta \\
Bitkiye Yarayışlı $\mathrm{Zn}$ & $(\mathrm{ppm})$ & DTPA-ICP & 0.97 & Yeterli \\
Bitkiye Yarayışlı $\mathrm{Cu}$ & $(\mathrm{ppm})$ & DTPA-ICP & 1.7 & Fazla \\
\hline
\end{tabular}

Denemenin kurulduğu kivi bahçesinde kış ve yaz budamaları yapılmış, bahçenin toprak analiz sonuçlarına göre standart gübre uygulaması yapılmıştır. Araştırmada kontrol uygulamalarına içerisinde saf su bulunan sırt pülverizatörü ile omcalar tamamen ıslatılmıştır.
Araştırmada, tam çiçeklenme döneminden beş hafta sonra olacak şekilde $50 \mathrm{~mL} 100 \mathrm{~L}^{-1}$ forchlorfenuron (CPPU), hasattan altı hafta önce olacak şekilde 20 ppm $\mathrm{GA}_{3}$, hasattan altı hafta önce olacak şekilde $2 \mathrm{mM} \mathrm{OA}$, tam çiçeklenmeden altı hafta sonra olacak şekilde 25 
ppm IBA, tam çiçeklenmeden altı hafta sonra olacak şekilde 50 ppm perlan uygulamaları yapılmıştır.

\section{Kimyasal analizler}

\section{Suda çözülebilir kuru madde miktarı (SÇKM)}

Meyvelerin suda çözülebilir kuru madde (SÇKM) miktarı 3 yinelemeli olarak gerçekleştirilmiştir. Suda çözülebilir kuru madde miktarının ölçülmesi amacıyla elde edilen meyve sularından birkaç damla alınmış ve ölçüm dijital refraktometre yardımıyla \% olarak belirlenmiştir. Yapılan ölçümlerin ortalaması SÇKM değeri olarak alınmıştır. (Öztürk, 2012).

\section{Titre edilebilir (TEA) asit miktarı}

Meyve suları sıkıldıktan sonra tortularından ayrılıp $10 \mathrm{~mL}$ alınmış ve saf su ile $100 \mathrm{~mL}$ 'ye tamamlanmıştır. Elde edilen karışımın $\mathrm{pH}^{\prime}$ sı 8.1 oluncaya kadar $1 \mathrm{~N} \mathrm{NaOH}$ ile titre edilmiştir. Harcanan $\mathrm{NaOH}$ miktarı belirlendikten sonra titre edilebilir asit miktarı \% olarak malik asit cinsinden hesaplanmıştır (Cemeroğlu, 2010).

\section{pH tayini}

Meyvelerin $\mathrm{pH}$ değerleri, elde edilen meyve suyundan el pH metresi ile ölçülerek belirlenmiştir (Öztürk, 2012) .

\section{Toplam fenolik madde miktarının belirlenmesi (mg GAE $\left.g^{-1}\right)$}

Toplam fenolik madde miktarı Singleton ve Rossi (1965)'nin belirttiği Folin-Ciocalteu's kimyasalı kullanılarak belirlenmiştir. Bu amaçla homojenize edilen meyve püresi aseton, su ve asetik asit (70:29.5:0.5) çözeltisi kullanılarak, bir saat boyunca tüpler içerisinde ekstraksiyon işlemine tabi tutulmuş ve daha sonra ekstraksiyonun üzerine Folin-Ciocalteu's kimyasalı ile saf su karıştırılarak 8 dakika karanlıkta bekletilmiştir. Devamında üzerine \% 7'lik sodyum karbonat ilave edilip iki saat inkübasyondan sonra çözeltinin absorbansı spektrofotometrede $750 \mathrm{~nm}$ dalga boyunda okunmuştur.

\section{Toplam flavonoid içeriğinin belirlenmesi ( $m g$ catechin $100 g^{-1}$ )}

Toplam flavonoid içeriği Kim ve ark. (2003) tarafından belirtilen yönteme göre yapılmıştır. Bu amaçla her örnekten $1 \mathrm{~mL}$ alınmış ve üzerine $0.3 \mathrm{~mL} 5 \% \mathrm{NaNO}_{2}$ solüsyonu eklenip karıştırılmıştır. 5 dakika inkübasyonun ardından üzerine $0.3 \mathrm{~mL} \% 10 \mathrm{AlCl}_{3}$ eklenip tekrar 6 dakika inkübasyona tabi tutulmuştur. İnkübasyonun ardından $2 \mathrm{~mL} 1 \mathrm{M} \mathrm{NaOH}$ eklenip 2 dakika tekrar inkübasyona bırakılmıştır. Daha sonra üzerine $4 \mathrm{~mL}$ saf su eklenip iyice karıştırılmış ve $510 \mathrm{~nm}$ dalga boyunda örneklerin absorbans değerleri okutulmuştur.

\section{Vitamin C miktarının belirlenmesi (mg $\left.100 \mathrm{~g}^{-1}\right)$}

Vitamin C miktarı Namdar (2005)'ın belirlediği yönteme göre $\mathrm{mg} / 100 \mathrm{~g}$ olacak şekilde saptanmıştır. Elde edilen veriler MiNITAB paket programı kullanılarak varyans analizine tabi tutulmuş ve önemli çıkan ortalamalar arasındaki farklıık TUKEY çoklu karşılaştırma testine ( $p$ $\leq 0.05$ ) göre belirlenmiştir.

\section{BULGULAR ve TARTIŞMA}

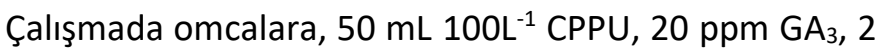
$\mathrm{mM}$ OA, 25 ppm IBA ve 50 ppm Perlan uygulanmış ve söz konusu bitki büyüme düzenleyicilerin meyvelerin biyokimyasal içerikleri üzerine etkisi incelenmiştir. Uygulamaların SÇKM, pH, TEA içerikleri üzerine etkisi Çizelge 2'de sunulmuştur. Araştırmada uygulamaların SÇKM bakımından kontrole göre etkisinin olmadığı, hatta istatistik olarak kontrol uygulaması ile aynı grupta yer aldığı belirlenmiştir. Uygulamaların $\mathrm{pH}$ değeri üzerine etkisi incelendiğinde, IBA ve $\mathrm{GA}_{3}$ uygulamalarının kontrol ve diğer uygulamalara göre istatistik olarak önemli farklar ortaya koyduğu, $\mathrm{GA}_{3}$ uygulamasının 3.53 ile en yüksek pH değeri değerine sahip olduğu belirlenmiştir. Uygulamaların TEA içeriği üzerine etkisi incelendiğinde, tüm uygulamalar arasındaki farkın istatistik olarak p $\leq 0.05$ düzeyinde önemli olduğu saptanmıştır. Araştırmada en yüksek TEA içeriği \%29.15 ile IBA uygulamasında saptanmış, bunu sırasıyla istatistik olarak aynı grupta yer alan \%29.11 ile OA ve \%28.44 ile perlan uygulaması takip etmiştir. En düşük TEA içeriği ise \%24.82 ile $\mathrm{GA}_{3}$ uygulamasında elde edilmiştir. Uygulamaların Vitamin $\mathrm{C}$, toplam fenolik madde içeriği ve toplam flavonoid içeriği üzerine etkileri Çizelge 3 'de sunulmuştur. Çalışma sonucunda uygulamaların vitamin $C$, toplam fenolik madde ve toplam flavonoid içerikleri üzerine etkilerinin istatistik olarak $p \leq 0.05$ düzeyinde önemli farklııklara neden olduğu saptanmıştır. Vitamin C içeriği bakımından en yüksek değer (123.04 mg $100 \mathrm{~g}^{-1}$ ) IBA uygulamasından elde edilirken bunu OA uygulaması (109.55 mg $100 \mathrm{~g}^{-1}$ ) takip etmiştir. En düşük vitamin C içeriği ise kontrol uygulamasında (82.97 mg $100 \mathrm{~g}^{-1}$ ) belirlenmiştir. Çalışmada en yüksek toplam fenolik madde içeriği CPPU (105.07 mg GAE $\left.100 \mathrm{~g}^{-1}\right)$ uygulamasında elde edilirken, bunu kontrol uygulaması (90.84 mg GAE $100 \mathrm{~g}^{-1}$ ) izlemiştir. Araştırmada en düşük toplam fenolik madde içeriği ise $\mathrm{OA}$ uygulamasında (56.34 mg GAE $100 \mathrm{~g}^{-1}$ ) saptanmıştır. Toplam flavonoid içeriği bakımından uygulamalar değerlendirildiğinde, en yüksek toplam flavonoid içeriğinin kontrol uygulamasında (18.95 mg CE $100 \mathrm{~g}^{-1}$ ) elde edilmiş, bunu sırasıyla CPPU (16.25 mg CE $100 \mathrm{~g}^{-1}$ ) ve perlan uygulaması (16.86 mg CE $100 \mathrm{~g}^{-1}$ ) izlemiştir. En düşük toplam 
flavonoid içeriğinin ise $\left(13.10 \mathrm{mg}\right.$ CE $\left.100 \mathrm{~g}^{-1}\right) \mathrm{GA}_{3}$ uygulamasından elde edildiği saptanmıştır. Bitki büyüme düzenleyiciler maddeler bitkiler tarafından oluşturulan ya da bitkiye dışarıdan verilen, bitkinin çimlenme, vejetatif büyüme, üreme, olgunlaşma ve yaşlanma gibi olayları gerçekleştiren maddelerdir (Kumlay ve Eryiğit, 2011).

Çizelge 2. Uygulamaların SÇKM, pH ve titre edilebilir asitlik değerleri üzerine etkisi

Table 2. Effects of applications on TSS, $\mathrm{pH}$ and titratable acidity values

\begin{tabular}{cccc}
\hline UYGULAMALAR & SÇKM (\%) & $\mathrm{pH}(\%)$ & Titre Edilebilir Asit (\%TEA) \\
\hline Kontrol & $5.67 \pm 0.12$ & $3.44 \pm 0.06 \mathrm{ab}$ & $26.04 \pm 0.43 \mathrm{~b}$ \\
Perlan & $5.29 \pm 0.59$ & $3.48 \pm 0.09 \mathrm{ab}$ & $28.44 \pm 0.53 \mathrm{a}$ \\
IBA & $5.69 \pm 0.25$ & $3.36 \pm 0.05 \mathrm{~b}$ & $29.15 \pm 0.32 \mathrm{a}$ \\
CPPU & $5.73 \pm 0.35$ & $3.42 \pm 0.06 \mathrm{ab}$ & $25.19 \pm 0.21 \mathrm{bc}$ \\
OA & $5.66 \pm 0.20$ & $3.40 \pm 0.03 \mathrm{ab}$ & $29.11 \pm 0.31 \mathrm{a}$ \\
GA $_{3}$ & $5.13 \pm 0.31$ & $3.53 \pm 0.029 \mathrm{a}$ & $24.82 \pm 0.22 \mathrm{c}$ \\
\hline
\end{tabular}

*Farklı harfle gösterilen ortalamalar arasındaki fark $\mathrm{p} \leq 0.05$ düzeyinde önemlidir.

Çizelge 3. Uygulamaların vitamin C, toplam fenolik madde ve toplam flavonoid içeriği üzerine etkisi

Table 3. Effects of applications on vitamin C, total phenolic content and total flavonoid content

\begin{tabular}{|c|c|c|c|}
\hline UYGULAMALAR & 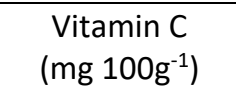 & 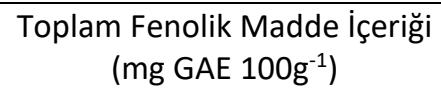 & $\begin{array}{l}\text { Toplam Flavonoid İçeriği } \\
\left.\text { (mg catechin } 100 \mathrm{~g}^{-1}\right)\end{array}$ \\
\hline Kontrol & $82.97 \pm 0.31 d$ & $90.84 \pm 1.81 \mathrm{~b}$ & $18.95 \pm 5.96 a$ \\
\hline Perlan & $104.97 \pm 3.31 b c$ & $74.22 \pm 0.98 c$ & $16.86 \pm 1.62 b$ \\
\hline IBA & $123.04 \pm 2.24 a$ & $73.07 \pm 1.80 c$ & $15.12 \pm 1.78 \mathrm{c}$ \\
\hline CPPU & $99.00 \pm 0.17 c$ & $105.07 \pm 3.58 \mathrm{a}$ & $16.25 \pm 1.96 b$ \\
\hline OA & $109.55 \pm 4.09 b$ & $56.34 \pm 0.902 \mathrm{e}$ & $14.85 \pm 1.64 d$ \\
\hline $\mathrm{GA}_{3}$ & $83.07 \pm 2.40 \mathrm{~d}$ & $65.65 \pm 1.657 d$ & $13.10 \pm 2.60 \mathrm{e}$ \\
\hline
\end{tabular}

*Farklı harfle gösterilen ortalamalar arasındaki fark $\mathrm{p} \leq 0.05$ düzeyinde önemlidir.

Bunlardan oksinlerin bitkilerde hücre bölünmesini, büyümesini ve gelişmesini hızlandırması, sitokininlerin hücre bölünmesini teşvik etmesi ve yaşlanmayı geciktirmesi, giberellinlerin bitkilerde uzamayı teşvik etmesi, oksalik asidin meyvelerde sekonder metabolit üretimini artırması, meyve verimini ve kalitesini olumlu yönde etkilemesi, benziladenin (6-BA) ve giberellin $\left(\mathrm{GA}_{4+7}\right)$ kombinasyonundan oluşan bir bitki büyümeyi düzenleyici olan perlan'ın ise ağaçlarda yan dal teşviki, bitkilerde fotosentez kapasite artışı, meyvelerde irilik, ağırlık, renk gelişimi gibi etkilere sahip olduğu bildirilmiştir (Stylianidis ve ark., 2004; Koyuncu ve Yıldırım, 2005; Kumlay ve Eryiğit, 2011; Martinez-Espla ve ark., 2014).

Araştırmada, uygulamaların SÇKM değerleri üzerine etkisinin istatistik olarak önemli olmadığı, ancak CPPU ve IBA uygulamalarının SÇKM değerlerinin kontrol grubu ile kıyaslandığında nispeten yüksek olduğu görülse de Perlan, $\mathrm{GA}_{3}$ ve $\mathrm{OA}$ uygulamalarının ise kontrolden daha düşük olduğu belirlenmiştir. Bazı araştırıcılar tarafından bitki büyümeyi düzenleyicilerin SÇKM içeriğinde artışa neden olduğu bildirilse de (Basak ve ark., 1998; Lenahan ve ark., 2006; Esen, 2009; Mohammadian ve Koldeh, 2010; Hosseinzadeh ve ark., 2013; Farzam ve ark., 2013) bazılarında ise artışa neden olmadığı rapor edilmiştir
(Facteau ve ark., 1985; Kappel ve Macdonald, 2002; Horvıtz ve ark., 2003). SÇKM değerlerindeki bu azalışın Perlan, $\mathrm{OA}$ ve $\mathrm{GA}_{3}$ uygulanan meyvelerin olgunlaşmasının yavaşlamasından kaynaklandığını çalışmamıza benzer şekilde önceki çalışmalarda da bildirilmiştir (Horvitz ve ark., 2003; Davarynejad ve ark., 2015). Çalışmamıza benzer şekilde Zhu ve ark. (2016) yaptıkları çalışmada hasat öncesi oksalik asit uygulamasının meyvelerde SÇKM değerlerinde kademeli olarak düşüşe neden olduğunu bildirmişlerdir. Ali ve ark. (2019) hasat öncesi kivi meyvesine oksalik asit uygulamışlar ve SÇKM değerlerinde kontrole göre önemli azalışlar belirlemişlerdir. Bununla birlikte standart olarak üretimi yapılan Hayward çeşidinin meyve iriliği, iç rengi, tat ve aromasının hasat zamanı bakımından oldukça farklı özellikler göstermektedir (Wang ve Buta, 2003). $\mathrm{GA}_{3}$ ve IBA uygulamalarının asitlik üzerine etkisi istatistiki olarak önemli bulunurken, Perlan, CPPU ve OA uygulamalarının etkisinin önemsiz olduğu tespit edilmiştir. Canlı ve Pektaş (2015) armutta perlan uygulamasının meyve suyu $\mathrm{pH}^{\prime}$ sında değişikliğe neden olmadığını yine benzer şekilde Canlı ve ark. (2015) perlan (BA+ $\mathrm{GA}_{4+7}$ ) uygulamasının kiraz meyvesinde asitlik üzerine etkisinin olmadığını bildirmişlerdir. Meyvelerin kimyasal içeriklerinin değişimi üzerine Bartın ilinin 
sıcaklık toplamı, nem düzeyi, gece gündüz arasındaki sıcaklık farkı, toprak yapısı ve nem düzeyi gibi faktörlerin de etki olabileceği göz ardı edilmemelidir. Meyvedeki asitlerin yoğunluk düzeyinin meyvenin tadını belirlediği ve düşük oranda bulunması durumunda meyveler tatlı, yüksek oranda bulunması durumunda ise ekşi özellik kazandıkları bilinmektedir (Kanbur ve Gündoğdu, 2020). Kivi meyvesi üzerine yapılan çalışmalarda kivi meyvesinin yeme olumuna yaklaştıkça asitliğinde de paralel şekilde artışların tespit edildiği bildirilmiştir (Samancı, 1990; Kaynaş ve ark., 2002; Altuntaş ve ark., 2009; Hosseinzadeh ve ark., 2013). Araştırmada, TEA oranları üzerine Perlan, IBA ve $O A$ uygulamalarının artışa neden olduğu, CPPU ve $\mathrm{GA}_{3}$ uygulamalarının ise aksine düşüşe neden olduğu saptanmıştır. Budak ve Şan (2017) hasat öncesinde $\mathrm{OA}$ ve $\mathrm{GA}_{3}$ uygulamalarının armut çeşitlerinde uygulamaların TEA oranı üzerine etkisinin olmadığını bildirmişlerdir. Araştırmada, tüm uygulamaların kontrole göre vitamin C içeriğini artırdığı saptanmıştır. En yüksek Vitamin C içeriğinin IBA (123.04 mg $\left.100 \mathrm{~mL}^{-1}\right)$ uygulamasında, en düşük ise kontrol $\left(82.97 \mathrm{mg}_{\left.100 \mathrm{~g}^{-1}\right)}\right.$ uygulamasında elde edildiği belirlenmiştir. Ben-Aire ve ark. (1982) yaptıkları çalışmada kivi meyvesinin olgunlaşması ile birlikte Vitamin C miktarının azaldığını bildirmişlerdir. Bununla birlikte bazı araştırıcılar çalışmamıza benzer şekilde bazı uygulamalarla kivide vitamin C miktarının arttığı, taze meyvede $37-200 \mathrm{mg}$ $100 \mathrm{~g}^{-1}$ arasında değiştiğini belirlemişlerdir (Selman, 1983; Lintas ve ark., 1991). Orduda yapılan bir çalışmada araştırma sonuçlarımıza benzer şekilde vitamin C

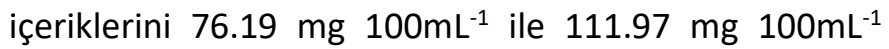
arasında (Bostan ve ark., 2014), Giresun koşullarında yapılan bir araştırmada çalışmamızdan düşük olacak

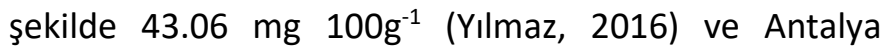
koşullarında yapılan bir çalışmada ise çalışmamıza

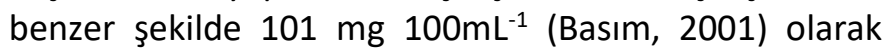
saptamışlardır. Önceki çalışmalarda da kivi meyvesinin vitamin C içeriğinin elma, şeftali, kiraz ve limon gibi meyvelerden daha yüksek olduğu bildirilmiştir (Beever ve Hopkirik, 1990; Mitchell, 1994). Kivide yüksek oranda bulunan $\mathrm{C}$ vitamininin antioksidan etkisi dışında yaraların iyileşmesi, diğer gıdalardan demir alımını artırması ve kolajen oluşumu açısından da çok etkili olduğu ifade edilmiştir (Ekşi ve Özen, 2012). Kivinin vitamin C içeriğinin çeşide, ekolojiye, olgunlaşma derecesine, depolamaya ve kullanılan analiz yöntemine bağlı olarak değişkenlik gösterdiği de ifade edilmektedir (Esti ve ark., 1998). Fenolik maddeler meyve ve sebzelere renk ve tadı veren, verim, kalite, büyüme ve gelişimde, bitkilerin stres koşullarında savunma mekanizmalarında önemli rol alan sekonder metabolitler içerisinde yer alan aromatik bileşiklerdir. Bununla birlikte fenolik bileşiklerin miktarları üzerine çeşit, ekolojik özellikler ve kültürel uygulamalar gibi faktörlerin etkili olduğu önceki çalışmalarda bildirilmiştir (Yıldırım ve ark., 2016). Araştırmada, toplam fenolik madde miktarı kontrole göre en yüksek CPPU uygulamasında (105.07 mg GAE $100 \mathrm{~g}^{-1}$ ) elde edilmiştir. Kubal ve ark. (2017) Ordu ilinde yaptıkları çalışmada Hayward çeşidinin toplam fenolik madde içeriğinin çalışmamızdan düşük olacak şekilde $45.70 \mathrm{mg}$ GAE $100 \mathrm{~g}^{-1}$ olarak bildirmişlerdir. Karakaya ve ark. (2019) Hayward kivi çeşidinde toplam fenolik madde içeriğini sonuçlarımıza göre yüksek olacak şekilde $613 \mathrm{mg}$ GAE $100 \mathrm{~g}^{-1}$ olarak saptamışlardır. Yine benzer şekilde Wu ve ark. (2004)'nın yaptıkları çalışmada kivi meyvesinin toplam fenolik madde düzeyini 378 mg GAE $100 \mathrm{~g}^{-1}$ olarak bildirilmiştir. Tavarini ve ark. (2008), yapmış oldukları çalışmada Hayward kivi çeşidinde belirlenen toplam fenolik madde içeriğini $219 \mathrm{mg} \mathrm{GAE} 100 \mathrm{~g}^{-1}$ olduğunu ifade etmişlerdir. Araştırmada toplam flavonoid içeriği en yüksek kontrol uygulamasından (18.95 mg catechin $100 \mathrm{~g}^{-1}$ ) elde edilmiştir. Wang ve ark. (2019), kivi meyvesinin flavonoidler bakımından zengin olduğunu, insanların immün sistemini güçlendirdiğini, kanser ve kardiovasküler hastalıklara karşı koruduğunu ifade etmişlerdir. Bununla birlikte sonuçlarımıza benzer şekilde toplam flavonoid içeriğini 26.60 (mg catechin $100 \mathrm{~mL}^{-1}$ ) olarak bildirmişlerdir. Du ve ark. (2009) yaptıkları çalışmada kivide toplam flavonoid içeriğini 6.64-74.24 (mg catechin $100 \mathrm{~mL}^{-1}$ ) arasında olduğunu bildirmişlerdir. Imeh ve Khokhar (2002), bitkilerin flavonoid içerikleri üzerine kültürel uygulamalar, çeşit ve ekoloji gibi faktörlerin etkili olabileceğini ifade etmişlerdir.

Kivi meyvesi düşük kalorili, yüksek oranda vitamin $C$ ve önemli miktarda klorofil ve karoten içermektedir (Wills ve Greenfield, 1981). Olgunluk aşaması, meyve ve sebzelerin bileşen kalitesini etkileyen bir diğer önemli faktördür. Meyve olgunlaşması sırasında çeşitli biyokimyasal, fizyolojik ve yapısal değişiklikler meydana gelmekte ve bu değişiklikler meyve kalitesini belirlemektedir (Ayala-Zavala ve ark., 2004). Sofralık ve sanayiye yönelik yapılan yetiştiricilikte ürün değerlendirme kriterleri değişiklik göstermektedir. Sofralık olarak tüketilecek kivi meyvelerinin iri ve meyve şeklinin düzgün olması tüketici tarafından daha fazla tercih edilmesini sağlamaktadır. Sanayiye yönelik üretimde meyve iriliği ve şekil önemli değildir. Meyve şekillerinde standart bir görünümün olmaması ürünün pazar değerini ve ürüne olan talebi düşürmektedir. Kivi meyvesinde hasat öncesi meyve kalitesi üzerine ise kısıtlı çalışmalar bulunmaktadır (Cangı ve ark., 2003; Kök, 2006; Soyergin ve ark., 2011). Araştırmada bitki büyüme düzenleyicilerin kivi meyvesinin biyokimyasal özellikleri 
üzerine etkileri incelenmeye çalışılmıştır. İnsan sağlığı üzerine yararlı etkileri olan kivi meyvesinin biyokimyasal içerikleri yönünden zengin olduğu ve bu anlamda karakteristik özelliklere sahip olduğu düşünülmektedir. Sonuç olarak kivi meyvesi, ülkemizde geç tanınan bir meyve olmasına karşın tüketiciler tarafından sıkça tercih edilmektedir. Ürüne olan bu talebin nedenleri arasında antioksidan etkisi ve içerdiği yüksek oranda vitamin $C^{\prime}$ dir. Hasat kriterleri bakımından değerlendirildiğinde meyvenin asitliği, içerdiği kuru madde miktarı, meyvenin şekli ve iriliği pazardaki değerini belirleyen unsurların başında gelmektedir. Dolayısıyla hasat öncesi bitki büyüme düzenleyiciler ile meyvelerin kalitesini arttırmaya yönelik çalışmalara öncelik verilmesi ve sonraki çalışmalara ışık tutacak şekilde literatüre katkı sağlaması önem arz etmektedir.

\section{ÖZET}

Amaç: Bu çalışmada, 'Hayward' kivi çeşidinin biyokimyasal içerikleri üzerine farklı bitki büyümeyi düzenleyici maddelerin etkisinin belirlenmesi amaçlanmıştır.

Yöntem ve Bulgular: Bu amaç doğrultusunda, omcalara tam çiçeklenmeden beş hafta önce $50 \mathrm{~mL} 100 \mathrm{~L}^{-1}$ Forchlorfenuron (CPPU), hasattan altı hafta önce 20 ppm Giberelik asit $\left(\mathrm{GA}_{3}\right)$ ve $2 \mathrm{mM}$ Okzalik asit $(\mathrm{OA})$, tam çiçeklenmeden altı hafta sonra $25 \mathrm{ppm}$ Indolbütirik asit (IBA) ve $50 \mathrm{ppm}$ Perlan uygulamaları yapılmıştır. Araştırma sonucunda meyvelerin toplam suda çözünebilir kuru madde (SÇKM), meyve suyu asitliği (pH), titre edilebilir asit (TEA), Vitamin C, toplam fenolik ve flavonoid madde içerikleri belirlenmiştir.

Genel Yorum: Uygulamalar sonrası SÇKM içeriklerinde istatistik olarak önemli farklar tespit edilmezken IBA ve $\mathrm{GA}_{3}$ uygulamalarının $\mathrm{pH}$ değerini arttırdığı ve bu artışın istatistik açıdan da önemli olduğu tespit edilmiştir. TEA değerlerinde kontrol uygulaması ile kıyaslandığında Perlan, IBA ve OA değerlerinde artışların olduğu saptanmıştır. Vitamin C bakımından zengin olduğu bilinen kivi meyvesinde yaptığımız çalışmada da yüksek oranlarda vitamin C içerdiği bir kez daha kanıtlanmış ve sonuçların literatür değerleri ile uyumlu olduğu tespit edilmiştir. Araştırmada toplam fenolik ve toplam flavonoid değerlerinde azalışlar meydana gelmiştir.

Çalışmanın Önemi ve Etkisi: Araştırmada bitki büyüme düzenleyicilerin kivi meyvesinin biyokimyasal özellikleri üzerine etkileri incelenmeye çalışılmıştır. İnsan sağlığı üzerine yararlı etkileri olan kivi meyvesinin biyokimyasal içerikleri yönünden zengin olduğu ve bu anlamda karakteristik özelliklere sahip olduğu düşünülmektedir.
Anahtar Kelimeler: Actinidia deliciosa, kivi, hayward, toplam fenolik madde, toplam flavonoid.

\section{ÇIKAR ÇATIŞMA BEYANI}

Yazarlar çalışma konusunda çıkar çatışmasının olmadığını beyan eder.

\section{ARAŞTIRMACILARIN KATKI ORANI BEYANI}

Yazarlar çalışmaya eşit oranda katkı sağlamış olduklarını beyan eder.

\section{KAYNAKLAR}

Ali M, Liu MM, Wang ZE, Li SE, Jiang TJ, Zheng XL (2019) Pre-harvest spraying of oxalic acid improves postharvest quality associated with increase in ascorbic acid and regulation of ethanol fermentation in kiwifruit cv. Bruno during storage. J. Integr. Agric. 18(11): 2514-2520.

Altuntaş E, Cangi R, Kaya C, Dilmaç M, Saraçoğlu O (2009) Hayward kivi çeşidinin hasat ve yeme olumu dönemlerindeki bazı fiziksel, mekanik ve kimyasal özelliklerinin belirlenmesi. III. Ulusal Üzümsü Meyveler Sempozyumu. Haziran 10-12, Kahramanmaraş. Bildiriler Kitabı: 293-301.

Anonim (2011) Bahçecilik: Kivi Yetiştiriciliği. Milli Eğitim Bakanlığı Yayını Ankara, 52 sayfa.

Anonim (2020) Tarım ve Orman Bakanlığı. Bitki koruma ürünleri.

https://bku.tarim.gov.tr/MRLUrunKoduAdBilgileri/D etails/53. (Son erişim tarihi:08.06.2020).

Ayala-Zavala JF, Wang SY, Wang CY, Gonzales-Aguilar AG (2004). Effect of storage temperatures on antioxidant capacity andaroma compounds in strawberry fruit. LWT 37: 687-695.

Basak A, Rozpara E, Grzyb Z (1998) Use of bioregulators to reduce sweet cherry tree growth and to improve fruit quality. Acta Horticulturae 468: 719-723.

Basım H (2001). Kivinin Antalya koşullarında mevsimsel gelişimi üzerinde araştırmalar. Yüksek Lisans Tezi, Akdeniz Üni., Fen Bil. Ens., Bahçe Bitkileri ABD,73 s.

Beever DJ, Hopkirik G (1990) Fruit development and fruitphysiology. Kiwifruits: Science and Management 97-126.

Ben-Aire R, Gross J, Sonego L (1982) Changes in ripening parameters and pigments of the chinese gooseberry (kiwi) during ripening and storage. Scientia Horticulturae 18: 65-70.

Bostan SZ, Günay K (2014) 'Hayward'(Actinidia deliciosa Planch) kivi çeşidinin meyve kalitesi üzerine rakım ve yöneyin etkisi. Akademik Zir. Derg. 3(1): 13-22. 
Budak MM, Şan B (2017) Hasat öncesi giberellik asit ve oksalik asit uygulamalarının 'kosiu' ve 'Hakko' asya armut çeşitlerinde meyve kalitesi üzerine etkileri. Zir. Fak. Derg. 12(2): 73-80.

Cangı R, Tarakçıŏlu C, Yalçın SR (2003) Potasyum sülfat ve potasyum humat gübre uygulamalarının Hayward kivi (Actinidia deliciosa) çeşidinde verim ve bazı meyve özellikleri üzerine etkisi. Tar. Bil. 9(4): 402-407.

Canli FA, Pektas M (2015) Improving fruit size and quality of low yielding and small fruited pear cultivars with benzyladenine and gibberellin applications. Eur. J. Hortic. Sci. 80(3): 103-108.

Chen H, Cheng Z, Wisniewski M, Liu Y, Liu J (2015). Ecofriendly hot water treatment reduces postharvest decay and elicits defense response in kiwifruit. Environ. Sci. Pollut. Res. 22(19): 15037-15045.

Davarynejad GH, Zarei M, Nasrabadi ME, Ardakani E (2015) Effects of salicylic acid and putrescine on storability, quality attributes and antioxidant activity of plum cv. 'Santa Rosa'. J. Food Sci. Tech. 52(4): 2053-2062.

Du G, Li M, Ma F, Liang D (2009) Antioxidant capacity and the relationship with polyphenol and vitamin $C$ in Actinidia fruits. Food Chem. 113(2): 557-562.

Ekşi A, Özen IT (2012) Kivi meyvesinin kimyasal bileşenleri ve fonksiyonel özellikleri. Ordu Üni. Tekn. Derg. 2: 54-67.

Esen Y (2009) Ünye yöresi kivi yetiştiriciliğinde meyve gelişiminin ve en uygun hasat zamanının belirlenmesi. Yüksek Lisans Tezi, Ondokuz Mayıs Üni., Fen Bil. Ens., Bahçe Bitkileri ABD, $123 \mathrm{~s}$.

Esti $M$, Messia MC, Bertocchi P, Sinesio F, Moneta E, Nicotra A (1998) Chemical compounds and sensory assessment of kiwifruit (Actinidia chinensis (Plance) var. chinensis): Electrochemical and Multivariate Analyses. Food Chem. 3: 293-300.

Facteau TJ, Rowe KE, Chestnut NE (1985) Response patterns of gibberellic acid-treated sweet cherry fruit at different soluble solids levels and leaf/fruit ratios. Scientia Horticulturae 27: 257-262.

Farzam E, Shahbazi H, Imani AA, Gheshlaghi EA (2013) Effect of harvest time on some qualitative and quantitative characteristics of hayward kiwifruit in the West of Gilan, Iran. Int. J. Farming and Allied Sci. 2(11): 296-301.

Ferguson AR (1991) Kiwifruit (Actinidia). Acta Horticulture 209: 603-653.

Food and Agriculture Organization (FAO) (2019) Statistical data for kiwifruit agriculture. http://www.fao.org/faostat/en/\#data/QC. (Erişim tarihi: 18.03.2021).
Horvitz S, Godoy C, Lopez Camelo AF, Yommı A, Godoy C (2003) Application of gibberellic acid to 'Sweetheart' sweet cherries: Effects on fruit quality at harvest and during cold storage. Acta Horticulturae 628: 311-316.

Hosseinzadeh J, Feyzollahzadeh M, Afkarı AH (2013). The physical and chemical properties of kiwifruit harvested at four stages. Bulg. J. Agric. Sci. 19(1): 174180.

Imeh U, Khokhar S (2002) Distribution of conjugated and freephenols in fruits: Antioxidant activity and cultivar variations. J. Agric. Food Chem. 50: 6301-6306.

Kahraman KA, Dardeniz A, Atak A (2018) Kivide (Actinidia spp.) meyve kalitesini etkileyen faktörler ve uygulamalar. Bahçe 47(1): 327-333.

Kanbur MŞ, Gündoğdu M (2020) Kivi meyvelerinin olgunlaşma evrelerine göre fenolik bileşik içeriklerindeki dağılım. Uluslararası Tarım ve Yaban Hayatı Bilimleri Dergisi 6(2): 194-201.

Kappel F, Macdonald RA (2002) Gibberellic acid increases fruit firmness, fruit size, and delays maturity of 'Sweetheart' sweet cherry. J. Am. Pomol. Soc. 56: 219-222.

Karakaya O, Öztürk B, Kadim H (2019) Kivi (Actinidia deliciosa cv. Hayward) meyvesinin biyoaktif bileşikleri üzerine farklı map uygulamalarının etkisi. Uluslararası Tarım ve Yaban Hayatı Bilimleri Dergisi 5(1): 11-17.

Kaynaş K, Dardeniz A, Kaya S (2002) A research on determining the most suitable harvest maturiyt of the kiwifruits (Actinidia deliciosa cv. Hayward) harvested at different time intervals. Pakistan J. Appl. Sci. 2 (12): 1074-1077.

Kim DO, Jeong SW, Lee CY (2003) Antioxidant capacity of phenolic phytochemicals from various cultivars of plums. Food Chem. 81(3): 321-326.

Koyuncu F, Yıldırım AN (2005) Induction of lateral branching of '0900 Ziraat' sweet cherry in the nursery with 6-benzyladenine+ GA4+ 7. In V International Cherry Symposium 795, pp. 391-394.

Kök EBD (2006) Kivide (Actinidia deliciosa) farklı dozda karpit uygulamalarının bazı meyve kalite kriterlerine etkileri. Tekirdağ Zir. Fak. Derg. 3(2): 213-219.

Kubal C, Bostan SZ, Mazı BG (2017) Ordu'da (Türkiye) yetiştirilen 'Hayward' kivi çeşidinin önemli kimyasal bileşenleri ve fiziksel özellikleri. Nevşehir Bilim ve Teknoloji Dergisi 6: 280-296.

Kumlay AM, Eryiğit T (2011) Bitkilerde büyüme ve gelişmeyi düzenleyici maddeler: bitki hormonları. Iğdır Üni. Fen Bil. Ens. Derg. 1(2): 47-56.

Lenahan OM, Whiting MD, Elfving DC (2006) Gibberellic acid inhibits floral bud development and improves 'Bing' sweet cherry fruit quality. HortScience 41: 654659. 
Lintas C, Adorisio S, Cappelloni M, Monastra E (1991) Composition and nutritional evaluation of kiwifruit grown in Italy. N. Z. J. Crop Hortic. Sci. 19: 341-344.

Martinez-Espla A, Zapata PJ, Valero D, Garcia-Viguera C, Castillo S Serrano M (2014) Preharvest application of oxalic acid increased fruit size, bioactive compounds, and antioxidant capacity in sweet cherry cultivars (Prunus avium L.). J. Agri. Food Chem. 62: 3432-3437.

Mitchell FG (1994) Composition, maturity and quality. In: Kiwifruit Growing and Handling (Eds: Hasey JK, Johnson RS, Grant JA, Reil WO). Publication 3344, Univ. of California Division of Agriculture and Natural Resources, Oakland, CA. pp 94-98.

Mohammadian MA, Koldeh JR (2010) The comparison of carbohydrate and mineral changes in three cultivars of kiwifruit of Northern Iran during fruit development. Aust. J. Crop Sci. 4 (1): 49-54.

Namdar S, (2005) Samsun ekolojik kosullarında yetistirilen hayward kivi çesidinin soğukta muhafazasında farklı ambalaj tiplerinin etkileri. Yüksek Lisans Tezi, Ondokuz Mayıs Üni., Fen Bil. Ens., Bahçe Bitkileri ABD, $132 \mathrm{~s}$.

Öztürk BE, Altuntaş E, Yıldız K, Özkan Y, Saraçoğlu O (2012) Effect of methyl jasmonate treatments on the bioactive compounds and physicochemical quality of 'Fuji' apples. Cien. İnvestig. Agrar. 40(1): 201-211.

Samancı H (1990) Kivi (Actinidia) Yetiştiriciliği, TAV Yayınları, Yalova, No:22, 112 sayfa.

Selman JD (1983) The vitamin C content of some kiwifruits (Actinidia chinensis Planch, variety 'Hayward'). J. Sci. Food Agric. 47: 401-416.

Singleton VL, Rossi JA (1965) Colorimetry of total phenolics with phosphomolybdic-phosphotungstic acid reagents. Am. J. Enol. Vitic. 16(3): 144-158.

Soyergin S, Atak A, Uysal E, Çelikel FG (2011) Yalova koşullarında organik kivi yetiştiriciliğinde kullanılan farklı bitki besleme uygulamalarının verim ve kaliteye etkisi. In: Organik Tarım Araştırmaları 2005-2010. TC Tarım ve Köyişleri Bakanlığı. pp. 169-174.

Stylianidis DK, Sotiropoulos TE, Vogiatzis D, Therios I, Koukourikou-Petridou M (2004) The effect of growth regulators on fruit shape and inorganic nutrient concentration in leaves and fruit of 'Red Delicious' apples. J. Biol. Res. 1: 75-80.
Tavarini S, Degl'Innocenti E, Remorini D, Massai R, Guidi L (2008) Antioxidant capacity, ascorbic acid, total phenols and carotenoids changes during harvest and after storage of Hayward kiwifruit. Food Chem., 107(1): 282-288.

Türkiye İstatistik Kurumu (TÜiK) (2020) https://biruni.tuik.gov.tr/medas/?kn=92\&locale=tr. (Erişim tarihi: 18.03.2021)

Wang CY, Buta JG (2003) Maintaining quality of fresh-cut kiwifruit with volatile compounds. Postharvest Biol. Tech. 28(1): 181-186.

Wang J, Vanga SK, Raghavan V (2019) High-intensity ultrasound processing of kiwifruit juice: Effects on the ascorbic acid, total phenolics, flavonoids and antioxidant capacity. LWT 107: 299-307.

Wills RBH, Greenfield H (1981) Methodological considerations inproducing data for food composition tables. Food Technology in Australia 33: 122-124.

Wu X, Beecher G.R, Holden JM, Haytowitz DB. Gebhardt SE, Prior RL (2004) Lipophilic and hydrophilic antioxidant capacities of common foods in the United States. J. Agric. Food Chem. 52: 4026-4037.

Yıldırım F, Yıldırım AN, Şan B, Ercişli S (2016) The relationship between growth vigour of rootstock and phenolic contents in apple Malus domestica. Erwerbs-Obstbau 58: 25-29.

Yılmaz B (2018) Giresun koşullarında yetiştirilen 'Hayward' kivi çeşidinde meyve gelişim sürecinde önemli kalite özelliklerinin değişimi. Ordu Üniversitesi Bilim ve Teknoloji Dergisi 8(2): 174-186.

Zhu Y, Yu J, Brecht JK, Jiang T, Zheng X (2016) Pre-harvest application of oxalic acid increases quality and resistance to Penicillium expansum in kiwifruit during postharvest storage. Food Chem. 190: 537-543. 